ISSN: $1980-055 X$

\title{
EVENTOS CLIMÁTICOS EXTREMOS NO OESTE PAULISTA E NORTE DO PARANÁ, NOS ANOS DE 1997, 1998 E 2001
}

\author{
André Geraldo Berezuk ${ }^{1}$ e João Lima Sant'Anna Neto
}

\begin{abstract}
RESUMO
O Oeste Paulista e o Norte do Paraná sempre se constituíram como importantes regiões para o estudo climático, dado que são regiões denominadas de transição, hora influenciadas por mecanismos atmosféricos de proveniência tropical, hora influenciadas por mecanismos atmosféricos de regiões temperadas ou polares. A coexistência dos sistemas quentes e frios, por sua vez, acarreta na gênese de eventos extremos e de adversidades climáticas, denominados em inglês hazards, que periodicamente originam prejuízos materiais nestas áreas, quando não ceifam vidas. $O$ artigo em questão, produzido segundo dados da tese "Análise das Adversidades Climáticas no Oeste Paulista e no Norte do Paraná", desenvolvida na FCT/UNESP de Presidente Prudente $\mathrm{SP}$, objetiva a interpretação das características físicas desses fenômenos nas cidades de Presidente Prudente, Maringá e Londrina, análise efetuada mediante utilização da técnica de análise rítmica de Monteiro. Os anos escolhidos para análise foram os de 1997 e 1998, considerados como chuvosos e o ano de 2001 considerado habitual. O artigo se focará em analisar tão somente os eventos, não se prendendo à utilização de médias estatísticas, evidenciando o aspecto não-linear e pontual desses fenômenos, uma das preocupações da técnica de análise rítmica.
\end{abstract}

Palavras-chave: Eventos extremos, análise rítmica, adversidades climáticas

\section{CLIMATE HAZARDS AT WESTERN SÃO PAULO AND NORTHERN PARANA STATES, IN THE YEARS OF 1997, 1998 AND 2001}

\begin{abstract}
The Western of Sao Paulo State and the Northern of Parana State in Brazil are always seen as main regions for climatic studies. They are named transitional climate areas because they are affected by tropical atmospheric disturbances or even influenced by extratropical atmospheric mechanisms. The coexistence of hot and cold systems origins extreme climate events called hazards, which periodically provoke material damage and people's death int these areas. This article was produced based on our work "Hazards Analysis in the Western of Sao Paulo State and the Northern of Parana State" sear-

1 Doutorando em geografia pela FCT/UNESP, Campus de Presidente Prudente, São Paulo, Brasil. E-mail: aberezuk@bol.com.br;

2 Professor Adjunto do Departamento de Geografia da FCT/UNESP, Campus de Presidente Prudente, São Paulo, Brasil. E-mail: joaolima@fct.unesp.br.
\end{abstract}


ched in the Science and Technology Center of the Sao Paulo State University (UNESP) in Presidente Prudente. We intended to show to the reader physical aspects of climate events that had happened in the cities Presidente Prudente, Maringa and Londrina. The analysis presented was developed based on the Monteiro's technique called rhythm analysis. We studied years which we considered humid (years 1997 - 1998) and another year (2001) classified as an habitual one. The work brings only the description of hazards: we do not mention statistics in order to show clearly the non-linear characteristics of the local where these events happened as we see that detailed description as one of the targets of the rhythm analysis skill.

Key-words: Extreme climatic events, rhythm analysis, hazards

\section{Introdução}

Quando o pesquisador se depara com a questão das adversidades climáticas, ele se depara com o elevado grau de complexidade dos fenômenos climáticos, notavelmente aleatórios, não-lineares, caóticos, mas que na desordem de seus fatores cria-se uma ordem harmônica, tal como se refere Monteiro (1989) após descrever sobre as contribuições da Teoria do Caos, com as contribuições de Lorenz e da Teoria Catastrofista de Thom, além de discernir sobre muitas outras contribuições a respeito desse tema. De fato, o estudo do caótico e o desafio de se analisar o que não segue uma seqüência ordenada como os fenômenos atmosféricos extremos é o que torna o estudo da variabilidade climática tão complexa e dos modelos atmosféricos tão polêmicos e debatidos (LENOIR, 1995).

Desse modo, para o estudo dos eventos extremos e da ocorrência dos hazards, tal qual Bryant (1993) faz alusão em suas pesquisas, a escolha da técnica no qual esses fenômenos serão analisados é de suma valia, no qual a técnica de análise rítmica proposta por Monteiro (1973) é totalmente válida. Essa técnica objetiva o estudo dos estados diários atmosféricos, chegando-se a uma noção do seu ritmo na área de estudo. Já conhecida dos estudos da Climatologia Brasileira, ela foi utilizada na tese "Análise de Adversidades Climáticas no Oeste Paulista e Norte do Paraná", desenvolvida na FCT/UNESP de Presidente Prudente - SP, que criou 108 gráficos de análise rítmica e 108 gráficos de eventos extremos, possibilitando o estudo de casos das adversidades climáticas das cidades de Presidente Prudente, Maringá e Londrina nos anos de 1997, 1998 e 2001.

\section{Material e métodos}

Para o estudo diário dos estados do tempo nos três anos propostos nas três cidades, foi necessária, primeiramente, a aquisição de uma grande quantidade de dados atmosféricos dotados de qualidade e contínuos que somente boas estações meteorológicas regionais dispõem. Esses dados foram obtidos, portanto, através das Estações Meteorológicas da: FCT/UNESP de Presidente 
Prudente - SP, Estação Climatológica Principal de Maringá - PR e Estação Meteorológica da IAPAR de Londrina - PR (Figura 1). Os fatores climáticos diários estudados (Figura 2) são os que possibilitarão, portanto, a criação dos gráficos de análise rítmica e de eventos climáticos (Figura 3 e 4) que permitirão a análise dos eventos extremos.

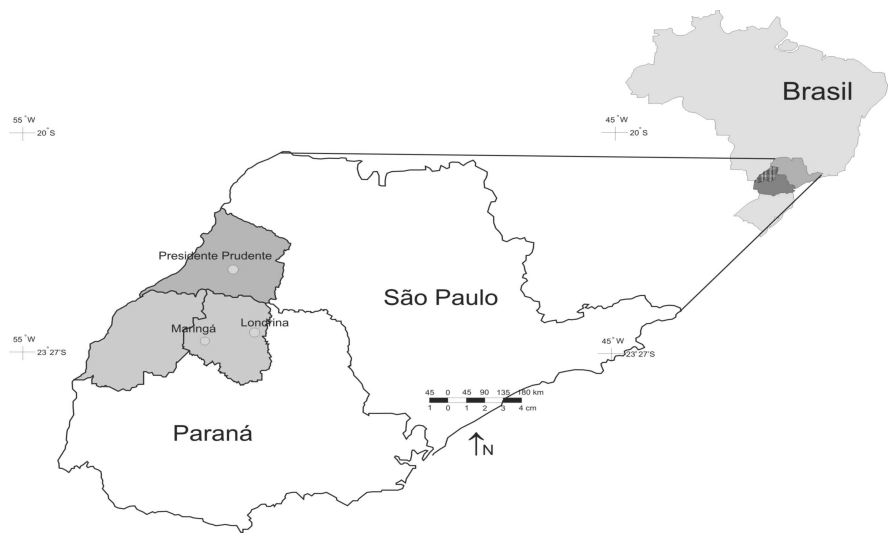

Figura 1. Área de localização das cidades e da região pesquisadas. Org: BEREZUK, A. G. (2006)

Análise do Comportamento Climático Regional (Análise Rítmica)

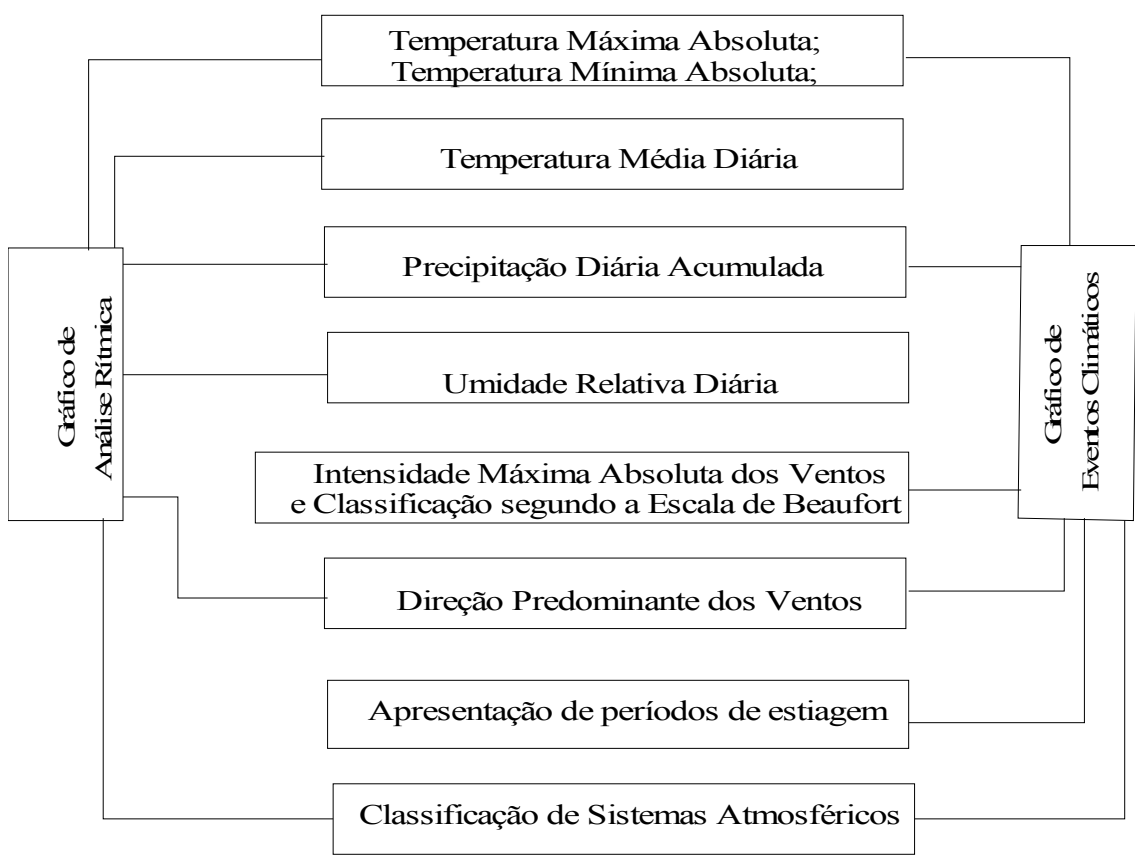

Figura 2. Gama de fatores climáticos estudados para a criação dos gráficos de análise rítmica e eventos climáticos 


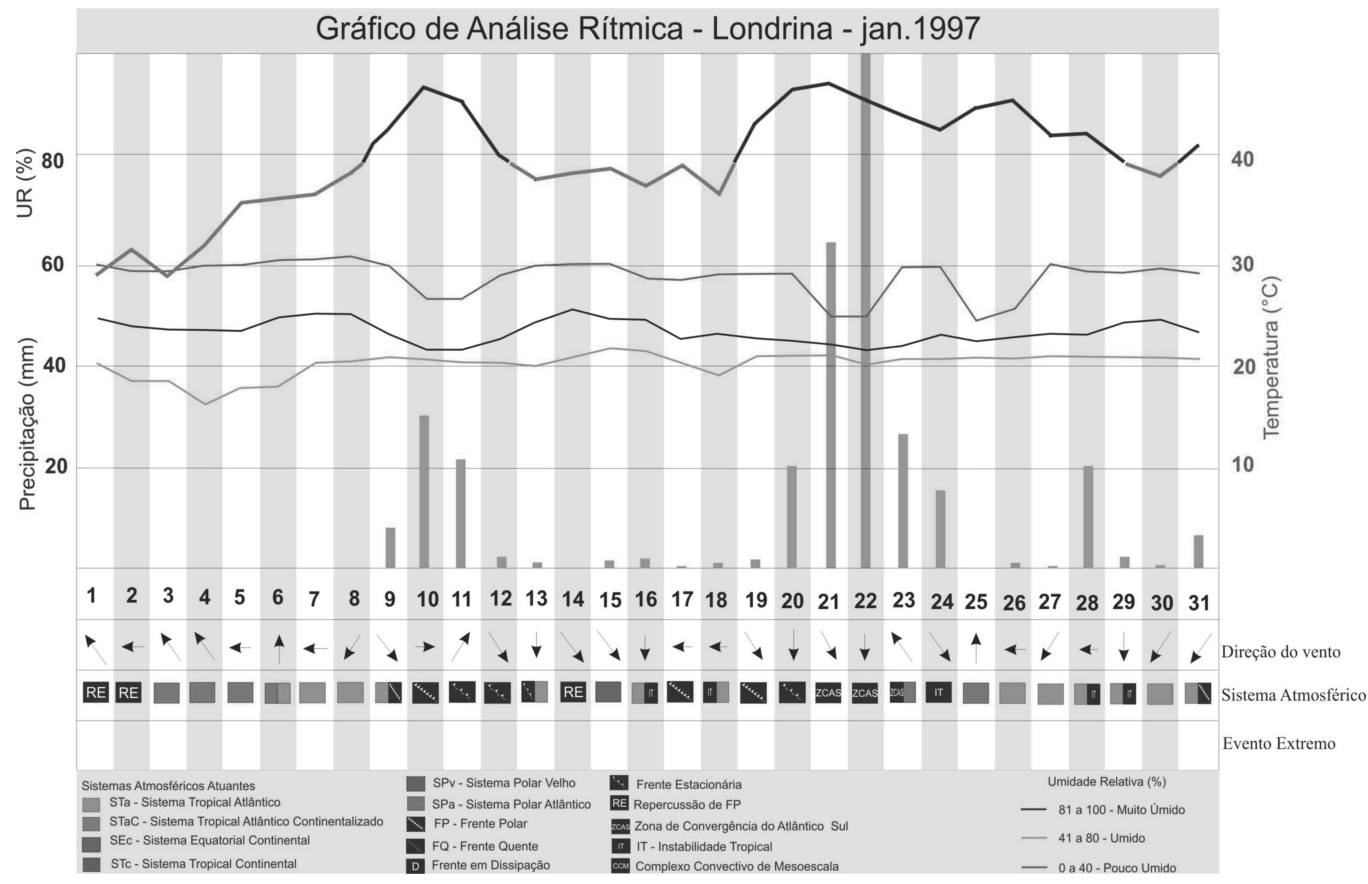

Figura 3. Gráfico de Análise Rítmica desenvolvido segundo dados das Estações Meteorológicas

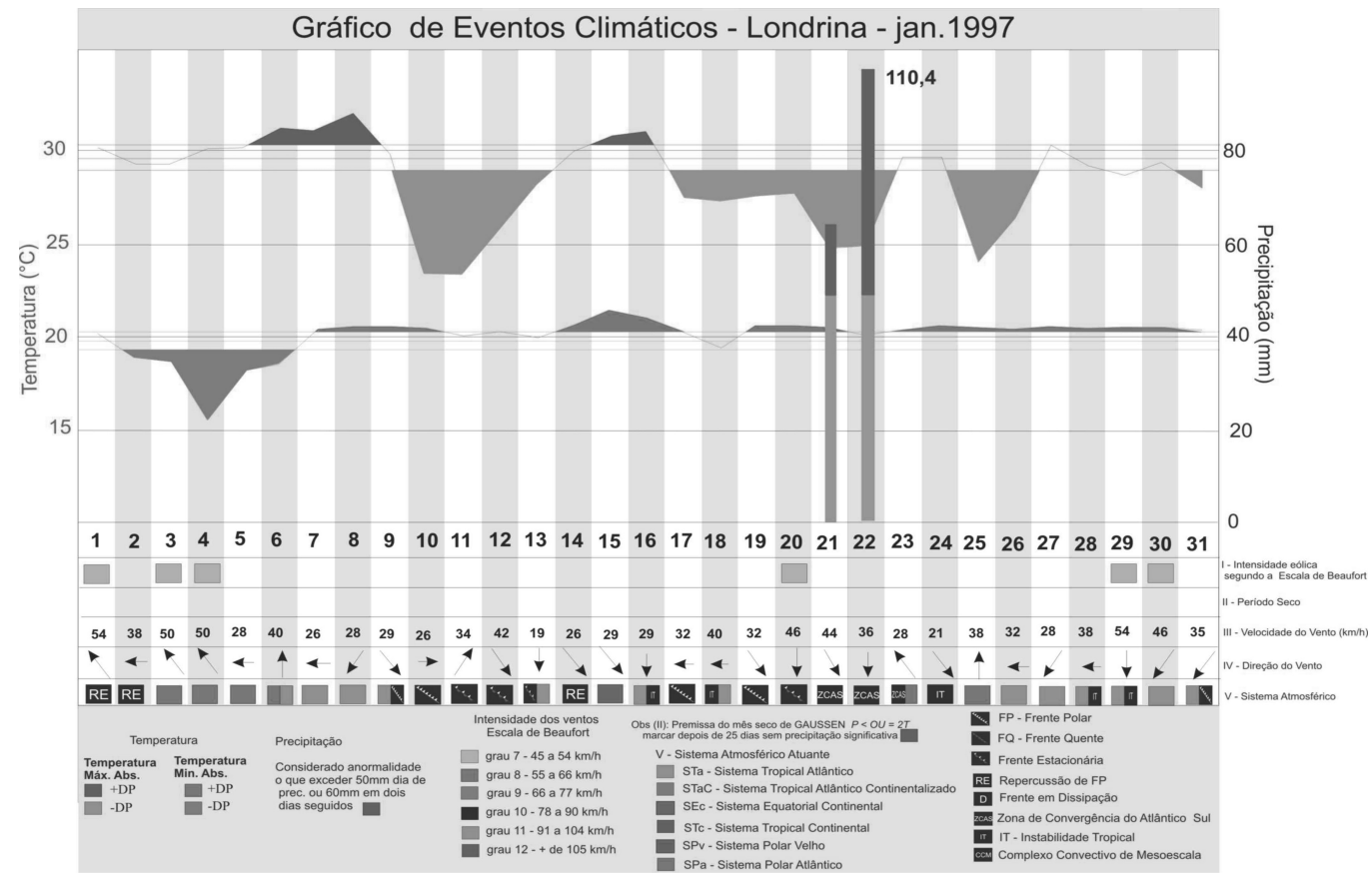

Figura 4. Gráfico de Eventos Climáticos desenvolvido segundo dados das Estações Meteorológicas 
Além dos dados diários das Estações Meteorológicas, foram analisadas 1095 cartas sinóticas, além de imagens de satélite. As imagens de satélite, muito importantes para o diagnóstico da ação dos sistemas atmosféricos diários, são provenientes do Instituto Nacional de Pesquisas Espaciais. As cartas sinóticas são, por sua vez, de responsabilidade do Serviço Meteorológico Marinho (Marinha do Brasil).

Com relação ao critério de escolha dos anos, o biênio 1997-1998 foi escolhido porque possuía características excepcionais devido ao fenômeno El Niño, apresentando estes anos aspecto chuvoso (além de serem mais recentes que os clássicos anos de 1982-1983 já muito estudados). O ano de 2001 foi escolhido pela necessidade de um ano com características mais habituais para contrapor aos dados do biênio chuvoso. Os anos de El Niño foram escolhidos, ao invés dos anos de La Nina, pelo fato de que a maioria dos casos de eventos extremos da região serem provenientes de chuvas intensas. Entretanto, mesmo no biênio estudado, significativos períodos de estiagem foram verificados, o que comprova novamente a grande aleatoriedade e complexidade do sistema atmosférico, e mesmo o ano de 2001, classificado como habitual em suas médias, apresentou eventos extremos tão ou mais intensos que os de 1997-1998. Os anos de La Niña também não fogem a essa característica, mesmo possuindo a tendência de ser um ano mais seco.

Escolhidos os anos e executada a técnica de análise rítmica, os casos de eventos extremos foram registrados nos gráficos, revelando os dias em que as três cidades foram alvos de seus impactos. A seguir, o artigo explanará brevemente os tipos de fenômenos extremos mais responsáveis pelas adversidades climáticas regionais registradas nos gráficos de análise rítmica e de eventos climáticos.

\section{Resultados e discussão}

Os exemplos de eventos extremos ocorridos nas cidades de Presidente Prudente, Maringá e Londrina segundo a análise rítmica dos anos de 1997, 1998 e 2001 podem ser inseridos em sua ampla maioria segundo quatro tipos característicos de fenômenos atmosféricos regionais:

1. A ação das ZCAS e suas chuvas;

2. Os intensos sistemas frontais;

3. As chuvas de verão (instabilidades tropicais);

4. Os períodos de estiagem/seca.

\section{A ação das ZCAS e suas chuvas}

A ação da Zona de Convergência do Atlântico Sul (ZCAS) é mais freqüente de setembro a março, agindo com maior intensidade de dezembro a fevereiro, causando constantes chuvas com significativos volumes. A ZCAS constitui-se, portanto, como uma extensa área de intensa nebulosidade e chuvas que 
corta o Brasil de noroeste a sudeste geralmente possuindo de 2000 a $2500 \mathrm{~km}$ de extensão (QUADROS, 1994). Não raro, essas chuvas são responsáveis pela origem de eventos extremos na área de estudo, tais como a ocorrência das chuvas de janeiro, fevereiro e novembro de 1997, ano de El Niño.

Tomando como exemplo desse fenômeno, as características atmosféricas registradas entre os dias de 19 a 23 de janeiro 1997 são dignas de nota. No dia 19 de janeiro ocorreu a passagem de uma frente fria sobre a área de estudo fazendo com que novamente a umidade relativa subisse acima dos $80 \%$. No entanto, a princípio, não foram registrados volumes significativos, apresentando Presidente Prudente a precipitação máxima de $18,8 \mathrm{~mm}$. Com relação à velocidade dos ventos, esses foram mais fortes em Presidente Prudente do que em Maringá e Londrina, chegando a apresentar rajada de $62 \mathrm{~km} / \mathrm{h}$. Convém lembrar que o mês de janeiro de 1997 apresentava-se, desde o dia 06, sujeito a chuvas constantes e umidade elevada, e, devido à constante presença da nebulosidade, com as temperaturas relativamente amenas para o mês.

No entanto, para uma melhor compreensão da formação de um meio propício à formação da ZCAS convém revelar o que ocorreu alguns dias antes. Foi constatado no dia 15, segundo as análises, uma possível incursão do Sistema Equatorial Continental sobre a área, mantendo elevada a umidade relativa e proporcionando um sistema atmosférico favorável para a passagem dos dois sistemas frontais citados. Assim sendo, no dia 17 de janeiro uma frente fria já tinha chegado à região, e logo dois dias depois, outro sistema frontal, a do dia 19. Desse modo, a grande facilidade de penetração de frentes frias em poucos dias, aliada a uma grande umidade do ar fornecida por essas frentes, pode ter originado condições para que, especialmente, a frente do dia 19 chegasse já à região do Oeste Paulista e Norte do Paraná muito lentamente, tornando-se estacionária nos dias 20 e 21 e configurando-se como ZCAS até o dia 23 . O resultado dessa configuração atmosférica foram dias seguidos de chuvas com volumes pluviométricos significativos (Figura 5). A partir do dia 24 a ZCAS migrou mais para o norte, diminuindo as chuvas na região.

Entretanto, as intensidades das chuvas apresentaram-se variadas para as três localidades. Presidente Prudente, que apresentou no dia 19 a maior quantidade de chuvas, não apresentou mais do que $10,4 \mathrm{~mm}$ até o dia 23 , representando mais uma "repercussão de ZCAS", ao contrário das cidades de Maringá e Londrina, que apresentaram até o dia 23,148,5 mm e 226,5 mm de precipitação. Além das chuvas intensas que esse fenômeno pode causar, não é incomum também que essas chuvas estejam acompanhadas de rajadas de ventos de até $60 \mathrm{~km} / \mathrm{h}$. No entanto a maior característica dessas chuvas é o seu volume pluviométrico, evocando-se a hipótese de que as rajadas de ventos mais intensas geralmente ocorrem, regionalmente, nos dias de chegada de sistema frontal e não quando existe a atuação de ZCAS, devido a maior variação de pressão atmosférica no dia de chegada dos sistemas frontais. Mas essa é uma hipótese que ainda deve ser mais bem analisada.

Além de janeiro de 1997, eventos climáticos relacionados à ZCAS nas três cidades ocorreram, por exemplo, em novembro de 1997 e fevereiro de 1998, com características semelhantes ao exemplo citado de janeiro de 1997.

Dias de chuvas seguidos, com volumes superiores a $50 \mathrm{~mm}$ em 24 horas podem afetar principalmente a pavimentação asfáltica das cidades, além 
das áreas mais vulneráveis, mais impactadas pelas fortes enxurradas, ocasionando, nos casos mais graves, ocorrência de desabrigados. Confirmando essas afirmações, segundo levantamento realizado por Souza (2005) e Berezuk (2006), 17 notícias de jornais relacionadas a adversidades climáticas só em janeiro de 1997 foram realizadas em Presidente Prudente e 10 notícias de jornais em Maringá, em sua ampla maioria, notícias relacionadas às chuvas excessivas proveniente da ação das ZCAS.
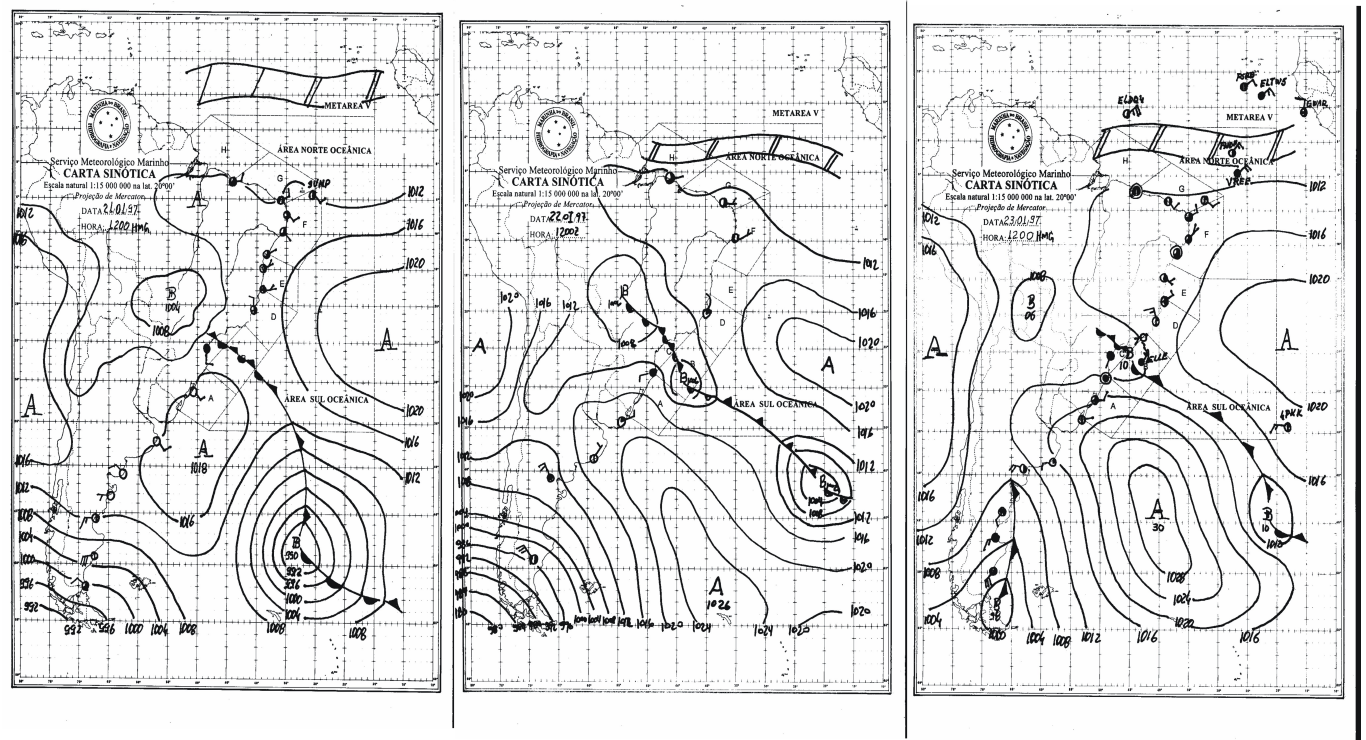

Figura 5. Configuração habitual de ZCAS no Oeste Paulista e Norte do Paraná (21 a 23/01/1997).

Fonte: SERVIÇO METEOROLÓGICO MARINHO, Cartas Sinóticas dos dias 21 a 23 de janeiro de 1997.

\section{Os intensos sistemas frontais}

A passagem de sistemas frontais pela área de estudo ocorre durante todo o ano. No entanto, cada frente fria apresenta suas peculiaridades, como a sua intensidade própria, o seu raio de ação e a velocidade de seu deslocamento, sendo essas frentes até classificadas, segundo Tubelis \& Nascimento (1983), como de deslocamento rápido ou de deslocamento lento. Dependendo, portanto, de fatores, como: o período do ano, a variação de pressão atmosférica ou a umidade relativa regional, essas frentes podem apresentar intensas rajadas de vento sem presença de chuvas significativas ou chuvas intensas sem a presença de rajadas de ventos fortes, a presença ocasional de granizo ou mesmo o surgimento de grandes tempestades.

Essa variedade de tipos de sistemas frontais é representada claramente nos gráficos de análise rítmica e eventos extremos. Em geral, nos dados apresentados, as rajadas de ventos atingem a velocidade absoluta de 40 a 50 $\mathrm{km} / \mathrm{h}$ na área de estudo, com precipitações geralmente superiores a $20 \mathrm{~mm}$. No entanto, essas frentes frias podem se apresentar ainda mais intensas, originando as adversidades climáticas mais freqüentes como os eventos de ventanias e 
temporais.

Muitos casos podem ser citados através da análise dos anos de 1997, 1998 e 2001 . Um deles, por exemplo, refere-se a um temporal ocorrido em Londrina em 19 de agosto de 1998, quando os ventos atingiram $79 \mathrm{~km} / \mathrm{h}$. O temporal atingiu também Presidente Prudente e Maringá, com os ventos chegando a $56 \mathrm{~km} / \mathrm{h}$ em Presidente Prudente. Com características próprias de um mês seco, a frente fria não proporcionou muita chuva, chegando essas chuvas somente ao volume de aproximadamente $20 \mathrm{~mm}$ nas três cidades pesquisadas. Essa regra não é uma constante nos meses secos, devido ao já comprovado caráter aleatório dos eventos extremos, mas esse padrão se repete na região nesses períodos. Já em outros meses mais úmidos como dezembro, os valores pluviométricos dos sistemas frontais tendem a ser maiores. Em 22 de dezembro de 2001 em Londrina, choveu $76 \mathrm{~mm}$ em $24 \mathrm{~h}$ e no dia seguinte $55 \mathrm{~mm}$, totalizando $131 \mathrm{~mm}$ em dois dias. Em Maringá, os valores foram mais modestos, com aproximadamente $50 \mathrm{~mm}$ nos dois dias (22 e 23/12), e aproximadamente $45 \mathrm{~mm}$ em dois dias em Presidente Prudente. Os ventos chegaram a $47 \mathrm{~km} / \mathrm{h}$ em Presidente Prudente e $43 \mathrm{~km} / \mathrm{h}$ em Londrina, no dia 22.

Com relação ao estudo dos sistemas frontais, é também freqüente que uma cidade seja fortemente atingida por um evento extremo, enquanto que outra pode ser pouco ou nada influenciada. Um exemplo disso é a da frente fria de 30 de março de 1998, quando Presidente Prudente apresentou um volume pluviométrico de 100,3 mm em 24 h, enquanto que em Londrina e Maringá esses valores não chegaram a $40 \mathrm{~mm}$ em 24 h (Figura 6).

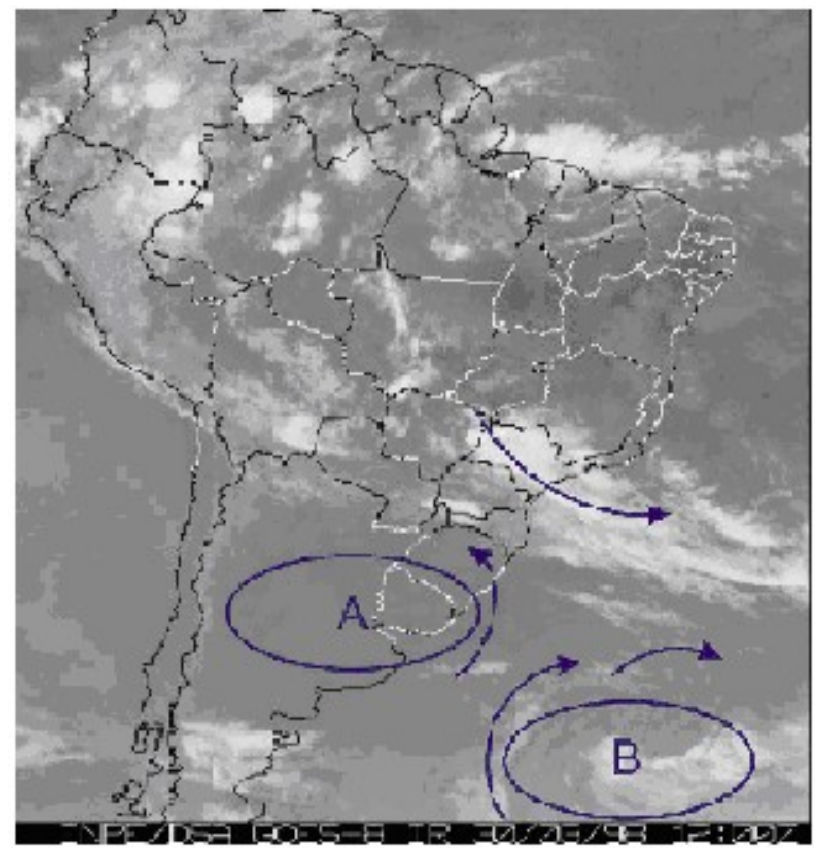

Figura 6. Ação de sistema frontal que causou volume pluviométrico de 100,3 $\mathrm{mm}$ em $24 \mathrm{~h}$ em Presidente Prudente - SP.

Fonte: Imagem de nuvens, INPE/GOES-8. 
Outro aspecto dos sistemas frontais regionais é de que a mesma cidade pode ser atingida por uma frente de uma determinada característica, e, logo após alguns dias, atingida por outra frente fria com características climáticas bem diferentes. Isso ocorreu em Presidente Prudente, quando em 04 de janeiro de 1998, após passagem frontal, a cidade recebeu $78,1 \mathrm{~mm}$ de chuva em $24 \mathrm{~h}$ e logo no dia 06 e 07 de janeiro a cidade é atingida por outra frente, que originou bem menos chuva que a primeira (menos de $10 \mathrm{~mm}$ de chuva), mas que propiciou ventos de até $85 \mathrm{~km} / \mathrm{h}$. Uma frente fria, portanto, propiciou chuvas intensas e os ventos não chegaram sequer a $20 \mathrm{~km} / \mathrm{h}$, sendo que, dois dias após, veio outra frente dotada de ventos muitos mais fortes e bem menos chuva.

Mesmo um sistema frontal apresentando, à primeira vista, um aspecto padrão, ele é sempre dotado de originalidade, onde a sua intensidade, medido em milibares $(\mathrm{mb})$, apresenta muita importância na previsão de eventos extremos.

Conforme analisado conjuntamente nas cartas sinóticas e gráficos de análise rítmica e eventos climáticos, sistemas frontais que apresentam, aproximadamente, na área de estudo, uma área de baixa pressão com valores abaixo de 1005 milibares (pressão atmosférica convertida para o nível do mar), podem ser indicativos em potencial de gênese de sistemas instáveis significativos, com a formação de temporais e tempestades regionais, ainda mais se a massa fria localizada atrás da área de frente for intensa, chegando a apresentar, por exemplo uma intensidade acima de 1020 milibares. Caso a área apresente nos dias préfrontais já uma umidade relativa elevada, o risco de eventos extremos aumenta ainda mais.

\section{As chuvas de verão (Instabilidades Tropicais)}

As chuvas de verão, também denominadas como Instabilidades Tropicais, não ocorrem somente no verão, mas também durante quase toda a primavera e até o início do outono, desde que a configuração atmosférica regional, dotada de grande presença de calor e umidade, ofereça condições para os processos de convecção. As nuvens de $I T$, que a princípio formam-se como cumulus, gradativamente continuam a se desenvolver verticalmente, tornando-se em cumulonimbus entre o período da tarde e início da noite, e assim originando, de modo freqüente, temporais localizados, com possibilidades de rajadas de ventos e queda de granizo.

Desse modo, não são raras as ocorrências de tempestades nas três cidades pesquisadas através da ação das ITs. Exemplos podem ser citados através da análise dos gráficos, como, por exemplo, a chuva do dia 23 de fevereiro de 2001 em Londrina, em que as rajadas de vento chegaram a $81 \mathrm{~km} / \mathrm{h}$ com uma precipitação de $31 \mathrm{~mm}$. No mesmo dia, em Presidente Prudente, os ventos chegaram a $65 \mathrm{~km} / \mathrm{h}$, mas com uma precipitação mais modesta. Contudo, dois dias após, na mesma Prudente, uma nova chuva de instabilidade tropical originou ventos de até $60 \mathrm{~km} / \mathrm{h}$, mas com o volume pluviométrico atingindo $70 \mathrm{~mm}$ (Figura 7). 

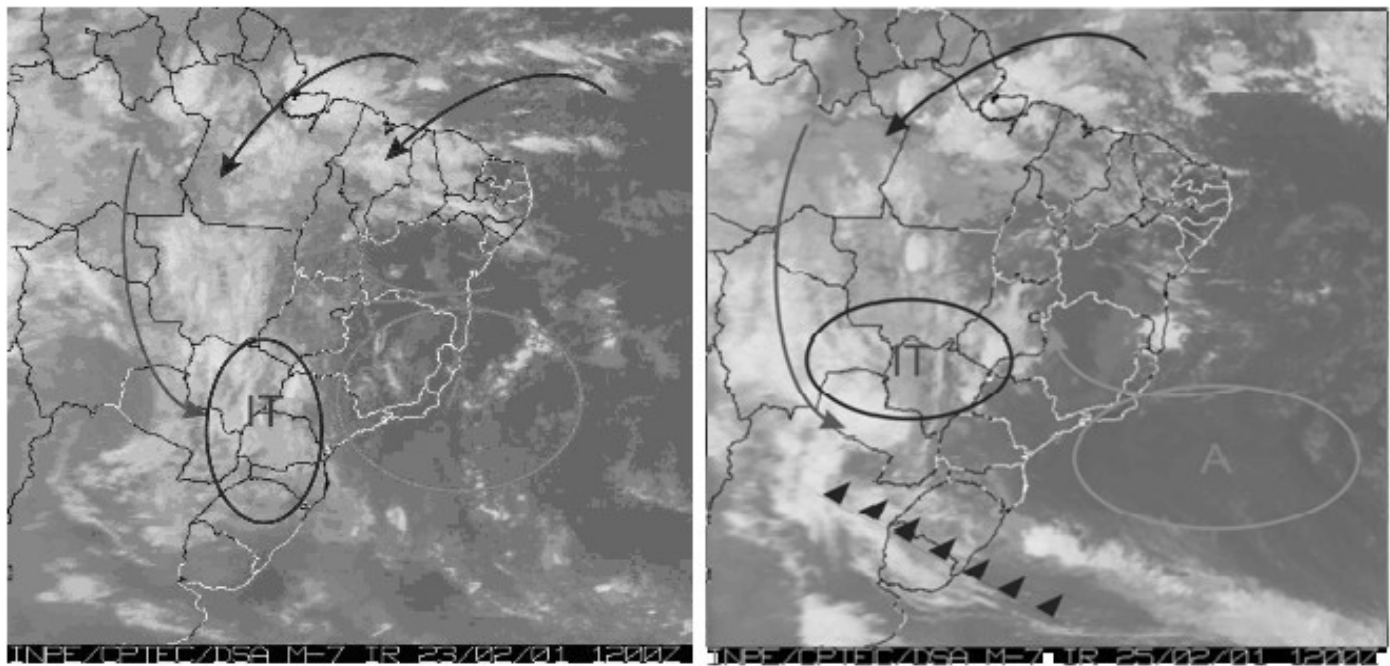

Figura 7. Configuração atmosférica dos dias 23 e 25 de fevereiro de 2001, com a presença de dias com fortes chuvas decorrentes de ação de Instabilidades Tropicais em Presidente Prudente e Londrina.

Fonte: Imagens de nuvens, INPE/GOES-8.
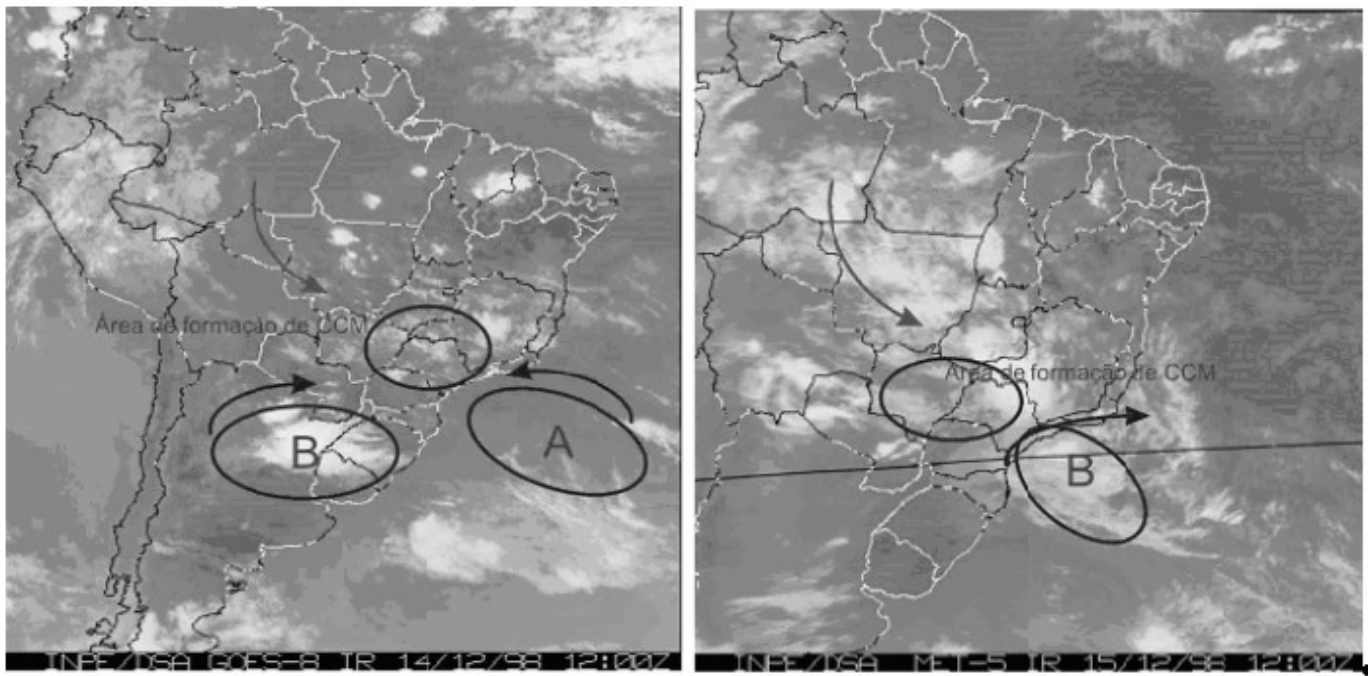

Figura 8. Configuração atmosférica dos dias 14 e 15 de dezembro de 1998 em que ocorreram fortes chuvas decorrentes de ação de Complexos Convectivos de Mesoescala em Presidente Prudente e Londrina.

Fonte: Imagens de nuvens, INPE/GOES-8.

Os eventos extremos regionais não somente se limitam à ação dos sistemas atmosféricos instáveis, pois, talvez, o mais impactante de seus eventos climáticos seja a ação contínua dos sistemas estáveis, impedindo a formação das chuvas, configurando os períodos de estiagem/seca. Ao contrário dos fenômenos pontuais e temporalmente breves dos temporais e ventanias, as secas abrangem quase sempre uma extensa área, podendo atuar por até mais de 70 dias, cau- 
sando perdas significativas nas lavouras, afetando os sistemas de abastecimento de água, originando períodos de crise na economia regional, além de causar mal-estar e doenças no dia a dia da população.

Convém lembrar que períodos de estiagem/seca são comuns no período que vai de junho a agosto na área analisada, já que nesses períodos, tradicionalmente, ocorre uma intensificação da ação do Sistema Tropical Atlântico, particularmente no sudeste brasileiro, oferecendo condições para que esse sistema possa se converter para um STaC (Sistema Tropical Atlântico Continentalizado). Desse modo, com o passar de aproximadamente duas semanas estáveis após a última frente fria, o ar frio proveniente do Sistema Polar tropicaliza-se, os ventos que a princípio de sul e sudeste passam a se tornar predominantemente de leste e nordeste, as temperaturas ficam acima da média para o período (configurando-se o veranico) e a porcentagem de umidade relativa decai para valores abaixo de $40 \%$. Essa configuração climática promove a formação de uma massa de ar quente que somente deixará a área com a chegada de um novo sistema frontal intenso.

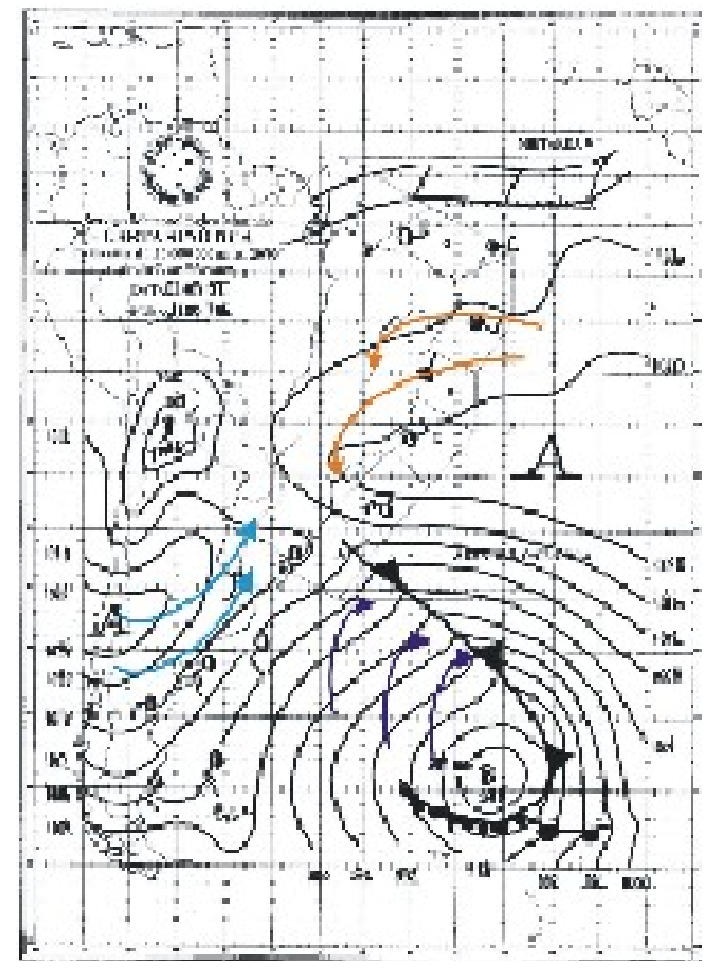

Figura 9. Exemplo do dia 02/05/1997, contribuindo com o período de estiagem no norte do Paraná e oeste paulista.

Fonte: SISTEMA METEOROLÓGICO MARINHO, Carta Sinótica do dia 02 de maio de 1997.

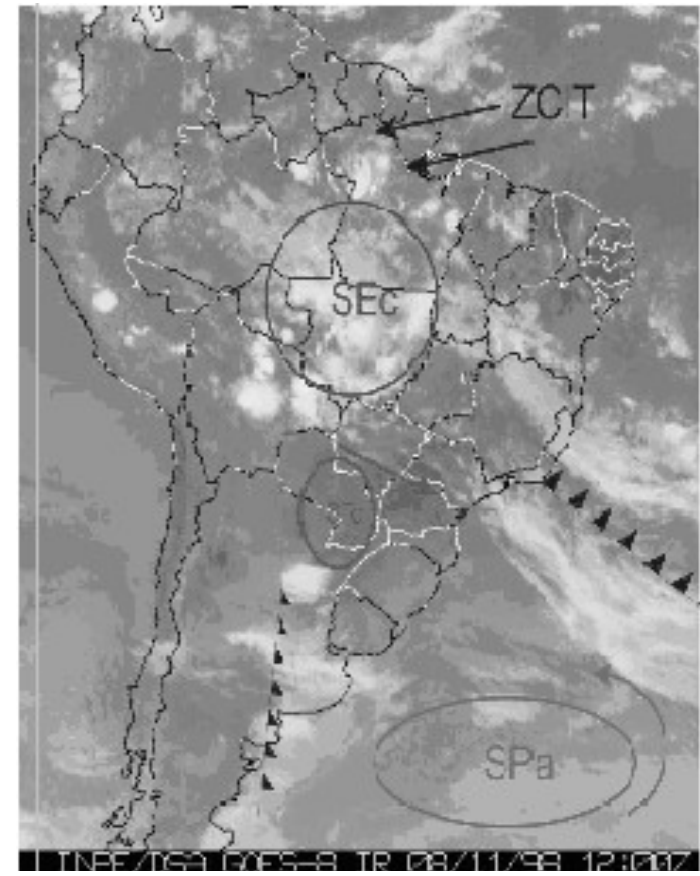

Figura 10. Exemplo de possível ação do Sistema Tropical Continental no dia 08 de novembro de 1998.

Fonte: SISTEMA METEOROLÓGICO MARINHO, Carta Sinótica do dia 08 de novembro de 1998 e Imagem de nuvens do dia 08 de novembro de 1998, INPE / GOES 8.

O problema torna-se mais sério quando o período de seca se estende por mais de 40 dias, atrasando o plantio da safra de verão. Quando esse período 
se estende para além do mês de setembro, a estiagem torna-se um evento de seca. Foi o que ocorreu em 1997 e 2001 na cidade de Presidente Prudente, que sofreu com um período de seca de aproximadamente 70 dias nesses dois anos. Mesmo sendo também atingidas pela seca, Maringá e Londrina apresentaram um período de seca menos agressivo, com as duas cidades mais bem servidas de chuvas provenientes das frentes frias, ao contrário de Prudente, localizada mais ao norte e mais influenciada pelo efeito da continentalidade.

Os períodos de estiagem/seca periodicamente ocorrem também fora dos meses de junho a agosto, podendo ser tão ou mais agressivos quanto os do período seco. Dois desses períodos podem ser citados na análise dos anos estudados: os meses de abril e maio de 1997 e os meses de novembro e dezembro (início) de 1998. Esses períodos de estiagem/seca ocorreram, assim como nos períodos habituais, devido a inibição de frentes frias na área, tal como ilustrado nas figuras 9 e 10. Na figura 9, a carta sinótica revela a passagem de um sistema ciclônico que atuou significativamente na Argentina e Uruguai, mas não trouxe chuva para o Oeste Paulista e Norte do Paraná, provendo a região somente do ar frio localizado atrás do sistema ciclônico, estendendo o período de estiagem por mais tempo. A imagem de nuvens da figura 10 revela a atuação do Sistema Tropical Continental, que com sua característica quente e seca inibia a passagem de sistemas frontais justamente na área estudada.

\section{Conclusões}

Segundo a observação das características referentes aos eventos extremos ocorridos nos anos de 1997 - 1998 - 2001, mediante análise rítmica desses anos, algumas considerações sobre os fenômenos atmosféricos descritos podem ser previamente efetuadas:

- As frentes frias, mesmo sempre apresentando um procedimento padrão em seu comportamento atmosférico, revelam intensidades variadas e sentidos de deslocamento variáveis dentro de uma área de tendência migratória. Suas intensidades dependem do período do ano em que elas estão atuando, do grau de atuação de fenômenos climáticos como o El Niño (La Niña) ou do Dipolo do Atlântico Sul, da temperatura e comportamento das correntes oceânicas próximas à costa brasileira e da umidade relativa regional, podendo esses sistemas frontais apresentar uma ampla gama de comportamentos climáticos. Segundo os gráficos de análise rítmica e eventos extremos, cada passagem frontal normalmente origina ventos com velocidade absoluta de 40 a $50 \mathrm{~km} / \mathrm{h}$ e chuvas acima de $20 \mathrm{~mm}$, mas dependendo da configuração regional atmosférica, as rajadas podem chegar a mais de $90 \mathrm{~km} / \mathrm{h}$ e as chuvas ultrapassarem a marca de 100 $\mathrm{mm}$ em $24 \mathrm{~h}$.

- A Zona de Convergência do Atlântico Sul, atuantes no período chuvoso da região, de setembro a março, com maior ênfase de dezembro a fevereiro, constituem-se como verdadeiros "repositores hídricos" regionais, com a atuação de suas intensas chuvas. As ventanias que acompanham periodicamente os aguaceiros podem causar estragos, além de possível queda de granizo. Entretanto, o volume pluviométrico parece se constituir como o personagem principal da atua- 
ção das ZCAS, sendo mais reservados para os eventos de entrada de frentes frias a participação mais constante das ventanias. No entanto, essas afirmações ainda carecem de mais estudos dos eventos extremos regionais.

- Além das ZCAS, as Instabilidades Tropicais agem com maior intensidade de setembro a março no Oeste Paulista e Norte do Paraná, com chuvas normalmente de curta duração, porém, periodicamente, com significativas intensidades e volume pluviométrico. Podem originar rajadas de ventos localizados, além de queda de granizo. Algumas vezes, as áreas de IT desenvolvem-se ainda mais, oferecendo condições para a formação de Complexos Convectivos de Mesoescala (CCM's). Esses apresentam a mesma característica das chuvas de Instabilidade Tropical, mas com uma maior abrangência de sua ação, podendo causar aguaceiros ou mesmo tempestades. A formação de CCM's está muitas vezes relacionada a uma pré-formação de ZCAS. A própria formação desses complexos convectivos está também relacionada à influência do calor e umidade provinda da ação do Sistema Equatorial Continental.

- Os períodos de estiagem/seca podem ser tão ou mais prejudiciais quanto os fenômenos relacionados aos sistemas instáveis. A grande diferença é que esses períodos possuem uma escala têmporo-espacial diferente dos fenômenos de ventanias e chuvas intensas, notadamente mais pontuais. Todavia, o significativo período de atuação do Sistema Tropical Atlântico e de sua variante Continentalizada, além da atuação do Sistema Tropical Continental, pode causar grandes preocupações às lavouras e aos sistemas de abastecimento de água, ainda mais se esses períodos ocorrerem fora do período habitualmente seco (junho a agosto), quando os níveis de evapotranspiração são maiores e o stress fisiológico das plantas, conseqüentemente também.

\section{Referências Bibliográficas}

BRYANT, E. A. Natural hazards. New York: Cambridge, 1993. 294 p.

ESTAÇÃO CLIMATOLÓGICA PRINCIPAL DE MARINGÁ - ECPM. Maringá-PR: Dados climatológicos diários correspondentes aos anos de 1997, 1998, 2001. Universidade Estadual de Maringá, 2005.

ESTAÇÃO CLIMATOLÓGICA DA FCT / UNESP DE PRESIDENTE PRUDENTE. Presidente Prudente-SP: Dados climatológicos diários correspondentes aos anos de 1997, 1998, 2001. Universidade Estadual Paulista "Júlio de Mesquita Filho", 2005. INSTITUTO AGRONÔMICO DO PARANÁ - IAPAR. Londrina-PR: Dados climatológicos diários correspondentes aos anos de 1997, 1998, 2001.

INSTITUTO NACIONAL DE PESQUISAS ESPACIAIS. Imagem de nuvens de 1998 e 2001. GOES 8.

LENOIR, Y. A verdade sobre o efeito de estufa: dossier de uma manipulação planetária. Lisboa: Caminho da ciência, 1995. 230 p.

MONTEIRO, C.A. de F. A dinâmica climática e as chuvas no Estado de São Paulo. São Paulo: Universidade de São Paulo, Instituto de Climatologia, 1973. 129 p.

Clima e Excepcionalismo. Florianópolis: UFSC - Universidade Federal de Santa Catarina, 1989. 226 p.

QUADROS, M. F. L. Estudo de episódios de zonas de convergência do Atlântico Sul (ZCAS) sobre a América do Sul. (Dissertação de Mestrado). São José dos 
Campos (SP) : INPE, 1994. $97 \mathrm{p}$

SERVIÇO METEOROLÓGICO MARINHO, Marinha do Brasil. Cartas Sinóticas dos anos de 1997, 1998 e 2001.

SOUZA, C.G. A análise dos episódios climáticos extremos no oeste paulista a partir das notícias veiculadas pela imprensa local. Presidente Prudente: FCT/ UNESP, 2005. 51 p. (Monografia) 